\title{
Temporal associative memory (TAM) by spike-timing dependent plasticity
}

\author{
David Tam \\ From Nineteenth Annual Computational Neuroscience Meeting: CNS*2010 \\ San Antonio, TX, USA. 24-30 July 2010
}

Spike-timing synaptic plasticity (STDP) describes the increase and decrease in synaptic strength depending on the relative arrival time of the pre- and post-synaptic spikes. The relative timing that determines whether the synapse is strengthened by long-term potentiation (LTP), or weakened by long-term depression (LTD) was first reported experimentally [1,2], and computationally [3]. Because of the asymmetry in timing, it is also called "temporally asymmetric Hebbian plasticity" theoretically [4]. Numerous studies on STDP had explored the biological mechanisms for induction of LTP and LTD. This paper will focus on the computational function of STDP in the formation of temporal associative memory (TAM). Traditionally, associative memory is often established relative to the spatial inputs, i.e., forming spatial memory. The formation of bidirectional associative memory [5] and spatiotemporal memory [6] using STDP has suggested that STDP can be used to encode spatiotemporal patterns. Our previous paper [7] also demonstrated that a time-delayed Hebbian associative network essentially computes the temporal relationship by the cross-correlation function between the pre- and post-synaptic input/output functions. The coefficients of cross-correlation can be retrieved by the final synaptic weights subsequent to the associative learning. The previous model only takes into account of Hebbian strengthening of synapses to establish the crosscorrelation function. We will extend this model to include STDP in the cross-correlation function to establish temporal association with time-delayed signals. The result suggests that temporal associative memory can be established by the contrast created by LTP and LTD.

Correspondence: dtam@unt.edu

Department of Biological Sciences, University of North Texas, Denton, TX 76203, USA

BioMed Central @ 2010 Tam; licensee BioMed Central Ltd.
Published: 20 July 2010

\section{References}

1. Markram H, Sakmann B: Action potentials propagating back into dendrites triggers changes in efficacy. Soc. Neurosci. Abs. 1995, 21.

2. Markram H, Lubke J, Frotscher M, Sakmann B: Regulation of synaptic efficacy by coincidence of postsynaptic APs and EPSPs. Science 1997, 275:213-5.

3. Gerstner W, Kempter R, van Hemmen JL, Wagner H: A neuronal learning rule for sub-millisecond temporal coding. Nature 1996, 383:76-81.

4. Matsumoto N, Okada M: Self-Regulation Mechanism of Temporally Asymmetric Hebbian Plasticity. Neural Computation 2002, 14(12):2883-2902

5. Meunier D, Paugam-Moisy H: A "spiking" Bidirectional Associative Memory for modeling intermodal priming. Proceedings of the 2nd IASTED International Conference Neural Network and Computationnal Intelligence. February 23-25 Grindelwald, Switzerland Acta Press88986-389-1 2004, 25-30.

6. Yoshioka M, Scarpetta S, Marinaro M: Spike-Timing-Dependent Synaptic Plasticity to Learn Spatiotemporal Patterns in Recurrent Neural Networks. ICANN 2007, Part I, LNCS 4668 Berlin Heidelberg: Springer-VerlagJ. Marques de Sá et al. 2007, 757-766.

7. Tam D: Theoretical Analysis of Cross-Correlation of Time-Series Signals Computed by a Time-Delayed Hebbian Associative Learning Neural Network. The Open Cybernetics \& Systemics Journal 2007, 1:1-4.

doi:10.1186/1471-2202-11-S1-P105

Cite this article as: Tam: Temporal associative memory (TAM) by spike-timing dependent plasticity. BMC Neuroscience 2010 11(Suppl 1): P105.

Submit your next manuscript to BioMed Central and take full advantage of:

- Convenient online submission

- Thorough peer review

- No space constraints or color figure charges

- Immediate publication on acceptance

- Inclusion in PubMed, CAS, Scopus and Google Scholar

- Research which is freely available for redistribution

Submit your manuscript at www biomedcentral.com/submit 